OPEN ACCESS

Edited by:

Ana Preto,

University of Minho, Portugal

Reviewed by:

Parames C. Sil,

Bose Institute, India

Amilcare Barca

University of Salento, Italy

*Correspondence:

Valerio Pazienza

pazienza_valerio@yahoo.it

Specialty section:

This article was submitted to

Cancer Metabolism,

a section of the journal

Frontiers in Oncology

Received: 17 February 2020

Accepted: 09 April 2020

Published: 22 May 2020

Citation:

Panebianco C, Latiano T and

Pazienza V (2020) Microbiota

Manipulation by Probiotics

Administration as Emerging Tool in

Cancer Prevention and Therapy.

Front. Oncol. 10:679.

doi: 10.3389/fonc.2020.00679

\section{Microbiota Manipulation by Probiotics Administration as Emerging Tool in Cancer Prevention and Therapy}

\author{
Concetta Panebianco ${ }^{1}$, Tiziana Latiano ${ }^{2}$ and Valerio Pazienza ${ }^{1 *}$ \\ ${ }^{1}$ Division of Gastroenterology, Fondazione IRCCS Casa Sollievo della Sofferenza, San Giovanni Rotondo, Italy, ${ }^{2}$ Oncology \\ Department, Fondazione IRCCS Casa Sollievo della Sofferenza, San Giovanni Rotondo, Italy
}

A growing body of literature indicates that microbiota plays a significant role in the development and curability of cancer, essentially due to the microbial ability to modulate immune and inflammatory responses to cancer and therapeutic treatments. Probiotics consumption, either in the form of food or supplements, is an easy and feasible way to manipulate microbiota composition and a number of recent researches have shown that it may represent a valid approach to prevent cancer onset and progression, to improve the clinical efficacy of the current anticancer treatments, and to mitigate the harmful adverse events of chemo- and radiotherapy, which often lead to scale drug doses, to delay or interrupt treatments. In this review, we gather the main in vivo studies on the current topic, focusing on the beneficial effects and underlying mechanisms provided by bacterial and yeast probiotics and their combination, in the setting of various types of cancers and different therapeutic protocols. These findings will likely open the way to consider, in future, regular probiotics intake as an adjuvant strategy in cancer prevention and management.

Keywords: microbiota, prebiotic, animal model, cancer, cancer therapies

\section{INTRODUCTION}

Cancer is a global health burden, representing the second leading cause of death all over the world. According to the World Health Organization (WHO), it is estimated that about one-third of deaths from cancer are caused by modern behavioral and dietary habits, including low fruit and vegetable consumption, sedentary lifestyle, obesity, smoking, and alcohol intake ${ }^{1}$. Among these modifiable risk factors, a growing interest in diet impact on health and disease has been fueled by the blooming of microbiota studies following the disclosure of the so-called "our other genome," a gene catalog of the human gut microbiome (1). It has been largely demonstrated that gut microbiota has a key role in maintaining health status and that food is one of the main tools to shape its composition $(2,3)$. The impact of different dietary patterns and food constituents on microbiota composition has been exhaustively reviewed elsewhere $(2,4,5)$. Particular relevance to human health is given to the intake of fruits and vegetables as a source of indigestible fibers, which are known to benefit the host gut environment by selectively promoting the growth of beneficial bacteria, known as "probiotics." The term "probiotic" comes from the Latin preposition "pro," which means "for, in favor of" and the Greek word "bios" meaning "life" and, according to the definition by the WHO, refers to "live microorganisms, which, when administered in adequate

${ }^{1}$ https://www.who.int/news-room/fact-sheets/detail/cancer 
amounts, confer a health benefit on the host" (6). Probiotics can be introduced in the form of food (such as yogurt, kefir, milk products, and fermented foods) or as supplements, and arrive alive in the intestine. The mechanisms through which these beneficial microbes influence host health include synthesis of vitamins and essential amino acids, production of metabolites such as short chain fatty acids derived from fibers' fermentation, reinforcement of the intestinal mucosal barrier, defense against pathogen colonization, detoxification of carcinogenic compounds, and stimulation of the host immune system $(2,7)$. Most probiotics belong to the genera Bifidobacterium and Lactobacillus, indigenous inhabitants of the human and animal gastrointestinal tract. Lactobacillus and other less common probiotics, such as Lactococcus, Enterococcus, and Streptococcus, are lactic acid bacteria, which convert sugars into lactic acid thus lowering the intestinal $\mathrm{pH}$ and hindering potentially pathogenic bacteria (8). Moreover, in addition to bacteria, yeast strains belonging to the genus Saccharomyces are also numbered among the probiotics (8).

Several studies have been carried out both in vitro and in vivo claiming the efficacy of probiotics in the prevention and treatment of cancer; however, since the real effect of probiotics can be evaluated only in in vivo studies (9), this review will summarize the main findings in human and animal studies concerning the ability of probiotics to affect cancer development, enhance effectiveness, or limit toxicity of the conventional anticancer treatments.

\section{PROBIOTICS IN CANCER PREVENTION AND PROGRESSION}

One of the best known and most investigated probiotic strains is Lactobacillus casei Shirota ( $\mathrm{LcS}$ ), a microorganism providing many health-favorable effects, mainly boosting the host immune system and preventing infectious gut diseases (10).

Several in vivo studies have evaluated the protective effects of LcS against different types of cancer (11-14). In a rat model of azoxymethane (AOM)-induced colon cancer, administration of a diet containing LcS significantly decreased carcinogenesis in terms of tumor incidence and multiplicity, likely by increasing the number of cytotoxic T lymphocytes (11). A later study on Japanese patients with a previous history of at least two colorectal cancers, showed that regular consumption of LcS, though not affecting the occurrence of new tumors, significantly reduced moderate and severe atypia (14). A case-control study carried out on Japanese women highlighted that regular intake of LcS in combination with isoflavones from soy since adolescence was protective against the risk of breast cancer (12). Replicating this experimental design in a rat model of chemically-induced breast cancer demonstrated that LcS consumption (alone and in combination with soymilk) decreased mammary tumor volumes (13). Also, Lactobacillus plantarum LS/07 was shown to slow mammary tumor growth in rats injured with 7,12 dimethylbenz[a]anthracene. Daily administration of this strain before and after cancer induction significantly decreased tumor frequency, increased $\mathrm{CD}^{+}$and $\mathrm{CD} 8^{+} \mathrm{T}$ cells in tumor tissues, and decreased $\mathrm{TNF} \alpha$ in the serum (15). Evidence of a cancer protective action was also provided for another strain of $L$. casei, namely L. casei BL23, which prevented colorectal cancer development in two different mouse models induced by 1,2dimethylhydrazine $(\mathrm{DMH})$ and $\mathrm{AOM}$, respectively $(16,17)$. In the first case, L. casei BL23 was found to modulate host immunity, shifting toward a Th17-response (16), whereas in the second case inhibition of cell proliferation and promotion of apoptosis by the probiotic were demonstrated (17). A breast cancerprotective action was demonstrated for Lactobacillus acidophilus ATCC4356 strain which, administered to mice before and after tumor implantation, significantly slowed its growth, increased the production of the T cell-stimulating IL-12, while decreasing that of the immunosuppressive TGF- $\beta$ (18). L. acidophilus, combined with Bifidobacterium bifidum and Bifidobacterium infantum also proved to be effective in reducing tumor incidence, multiplicity, and volume in a rat model of $\mathrm{DMH}$-induced colon cancer. Daily intake of this probiotic cocktail decreased the abundance of potentially pathogenic gut bacteria, reduced intestinal inflammation, and promoted the intestinal epithelial barrier function by enhancing TLR-2 signaling (19). Indeed, TLR-2 is a receptor for bacterial molecules whose stimulation maintains the integrity of intestinal tight junctions against injuries and whose deficiency disrupts epithelial barrier function, thus worsening colonic inflammation (20). Further, TLR-2 promotes colon cancerogenesis (21). Consistently, Kuugbee et al. (19) observed that increased expression of TLR2 upon probiotics administration was accompanied by higher levels of the junction proteins ZO-1 and occludin. Similar results were obtained by the same group when DMH-injured rats were administered daily with Lactobacillus rhamnosus GG: colon tumor incidence, multiplicity, and volume significantly decreased, in addition to intestinal inflammation (22). Again, in the setting of DMH-induced colon carcinogenesis, the probiotics Bacillus subtilis and Clostridium butyricum separately administered to cancer-induced mice significantly decreased tumor incidence and size, compared to injured mice not receiving probiotics. Inhibition of carcinogenesis was accompanied by a decreased number of Th2 and Th17 lymphocytes in the spleen and an increased number of $\mathrm{CD}^{+}$and $\mathrm{CD} 8^{+} \mathrm{T}$ cells in the peripheral blood of mice receiving $B$. subtilis or C. butyricum, compared to animals not administered with probiotics (23). Moreover, C. butyricum ATCC 19398 strain was tested against high fat diet-induced tumorigenesis in APC ${ }^{\mathrm{Min}}$ mice, genetically predisposed to intestinal neoplasms. Animals treated with this probiotic developed significantly less intestinal cancers, likely by modulation of gut microbiota and suppression of the $\mathrm{Wnt} / \beta$ catenin signaling (24). The latter is a pathway aberrantly activated in colorectal cancer, in which Wnt stimulation suppresses the $\beta$-catenin degradation system, resulting in its accumulation and nuclear translocation with consequent expression of target genes driving cell proliferation (25).

The commercially available probiotic cocktail VSL\#3 containing Lactobacillus plantarum, Lactobacillus delbrueckii subsp. bulgaricus, Lactobacillus paracasei, Lactobacillus acidophilus, Bifidobacterium breve, Bifidobacterium longum, Bifidobacterium infantis, and Streptococcus salivarius subsp. 
Thermophilus, known to alleviate colitis, was also shown to prevent colitis-associated adenocarcinoma in mice injured with dextran sulfate sodium (DSS). In particular, both prophylactic treatment before colitis induction and concurrent treatment with DSS led to decreased inflammation and reduced colonic dysplasia. Interestingly, even after 15 cycles of DSS, none of the mice receiving VSL\#3 concurrently with DSS developed adenocarcinoma, whereas $20 \%$ of animals receiving preventive VSL\#3 and $45 \%$ of mice not taking probiotics did (26). Furthermore, an Italian clinical study on human volunteers followed-up for 12 years after enrollment as concerns the development of colorectal cancer, verified an inverse association between yogurt (containing $S$. thermophilus and $L$. delbrueckii subsp. bulgaricus) consumption and colorectal cancer occurrence, which was more evident in men than in women (27).

In all the above-mentioned studies, the probiotic agent was represented by one or more bacterial strains, above all lactic acid bacteria; nevertheless, non-pathogenic yeasts, such as Saccharomyces boulardii, can also be listed in the family of probiotics $(8,28)$.

A study by Chen et al. demonstrated that daily S. boulardii administration to $\mathrm{APC}^{\mathrm{Min}}$ mice significantly reduced tumor number and size and the grade of dysplasia. These effects were mediated by the inhibition of EGFR and AKT proliferative pathways (29). More recently, S. boulardii administration to a mouse model of colitis-associated carcinogenesis induced by AOM/DSS was shown to reduce tumor incidence and size, to decrease colonic levels of the pro-inflammatory cytokines TNF- $\alpha$ and IL-6, and restore a balanced microbiota (30).

\section{PROBIOTICS AND ANTICANCER THERAPIES' EFFECTIVENESS}

In addition to cancer preventive action, some studies revealed a supportive role for probiotics toward chemotherapy, in terms of improved pharmacological response (31-33). A clinical trial on patients subjected to transurethral resection of bladder cancer treated with epirubicin showed that daily administration of LcS for 1 year significantly increased the recurrence-free survival compared to epirubicin alone, though not affecting progressionfree and overall survival (31). Effectiveness of L. acidophilus in boosting cisplatin action was provided in a mouse model of lung cancer: oral intake of this probiotic together with chemotherapy resulted in decreased tumor volume and extended survival with respect to cisplatin alone. These results were accompanied by lower expression of the oncoprotein VEGFA, higher expression of the tumor suppressors BAX and CDKN1B, and by increased serum levels of IL- 6 and IFN- $\gamma$ together with reduced levels of the immunosuppressive IL-10 in L. acidophilus/cisplatin combined treatment versus cisplatin alone (32). The use of a commercial probiotic mixture containing $L$. acidophilus, $L$. paracase $i$, two strains of $B$. lactis and B. bifidum turned out to be advantageous in enhancing 5-Fluorouracil (5-FU) action in a rat model of colorectal cancer induced by $\mathrm{DMH}$. Administration of probiotics together with chemotherapy attenuated the degree of tumor malignancy compared to 5-FU alone, since $40 \%$ of animals developed tubular adenoma and 60\% carcinoma in situ, compared to $100 \%$ of carcinoma in situ developed by rats only receiving chemotherapy (33).

Evidence has been provided to suggest that probiotics also improve the outcome of anti-cancer immunotherapy protocols (34-36). A mixture of B. bifidum, B. longum, B. lactis, and $B$. breve, administered to mice after melanoma implantation concurrent with anti-PD-L1 immunotherapy resulted in a significantly decreased tumor volume and increased number of tumor-infiltrating $\mathrm{CD}^{+} \mathrm{T}$ cells compared to anti-PD-L1 therapy alone (34). Apart from the most common probiotic microorganisms cited above, other less known bacteria demonstrated beneficial effects. Administration of Akkermansia muciniphila, alone or in combination with Enterococcus hirae, restored response to anti-PD1 therapy in melanoma or sarcomabearing mice with depleted gut microbiota, as demonstrated by reduced tumor size. This was likely due to an enhanced immunological response against the tumor, consisting in the accumulation of $\mathrm{CD} 4^{+} \mathrm{T}$ cells in mesenteric and tumor draining lymph nodes and in tumor bed, and in the increased secretion of IL-12, which normally synergizes anti-PD1 therapy (36). Finally, the impact of a daily administration of the probiotic Escherichia coli Nissle 1917 on anti-TGF- $\beta$ immunotherapy was evaluated in mouse models of hepatocellular and breast carcinoma. Markedly decreased tumor size, reduced Ki67 expression, increased apoptosis, inhibition of metastatic potential and shift from an immune-suppressive to an immune-stimulatory microenvironment were observed in combined treatment compared to immunotherapy alone (35).

Table 1 provides further details on the probiotic treatment scheme and the anticancer therapies' schedule followed in the above-mentioned studies.

A very recent preliminary study, however, suggests that the intake of probiotic supplements in melanoma patients lowers the response to anti-PD1 immunotherapy by $70 \%$, likely decreasing gut microbiota diversity (37). These controversial findings, which stand in conflict with the general perception of probiotics being beneficial and with previous results, deserve further investigations.

\section{PROBIOTICS AND ANTICANCER THERAPIES' TOXICITY}

Apart from improving their clinical efficacy, probiotics also hold promise for relieving some adverse reactions associated with the conventional anticancer treatments, which often make it necessary to scale drug doses and to delay or stop therapies. Intestinal damage represents a major debilitating complication of chemo- and radiotherapies, mostly presenting in the form of diarrhea and mucositis, a painful inflammatory/ulcerative condition of the mucosa (38).

Daily L. rhamnosus GG supplementation in colorectal cancer patients during 5-FU-based adjuvant chemotherapy was shown to decrease severe diarrhea, abdominal discomfort, and the need to reduce chemotherapy doses with respect to patients not receiving probiotics (39). Other probiotics have also been 
TABLE 1 | Effects of probiotic intake on anticancer therapies' effectiveness.

\begin{tabular}{|c|c|c|c|c|}
\hline Probiotic(s) & $\begin{array}{l}\text { Probiotic dosage and treatment } \\
\text { scheme }\end{array}$ & Therapeutic treatment scheme & Effect(s) & Reference \\
\hline L. casei Shirota & $\begin{array}{l}\text { Daily intake of } 3 \times 10^{10} \text { bacteria for } 1 \text { year, } \\
\text { starting after transurethral resection (TUR) } \\
\text { and the first two epirubicin instillations }\end{array}$ & $\begin{array}{l}30 \text { mg doses of epirubucin soon after TUR } \\
\text { and after } 1,3,4,6,8,10 \text {, and } 12 \text { weeks, } \\
\text { respectively }\end{array}$ & $\begin{array}{l}\text { Increased recurrence-free } \\
\text { survival in bladder cancer } \\
\text { patients }\end{array}$ & (31) \\
\hline L. acidophilus & Administration of $2 \times 10^{8} \mathrm{CFU} / \mathrm{mL}$ & $\begin{array}{l}\text { Intraperitoneal injection of } 5 \mathrm{mg} \\
\text { cisplatin/kg body weight }\end{array}$ & $\begin{array}{l}\text { Decreased tumor size and } \\
\text { extended survival in mice } \\
\text { with implanted lung cancer }\end{array}$ & (32) \\
\hline $\begin{array}{l}\text { L. acidophilus }+L \text {. } \\
\text { paracasei }+ \text { two } \\
\text { strains of } B \text {. lactis }+ \\
\text { B. Bifidum }\end{array}$ & $\begin{array}{l}\text { Daily administration of } 1 \times 10^{9} \mathrm{CFU} \text { for } 10 \\
\text { weeks }\end{array}$ & $\begin{array}{l}\text { A weekly dose of } 15 \mathrm{mg} \text { of } 5 \text {-FU/kg body } \\
\text { weight for } 10 \text { weeks }\end{array}$ & $\begin{array}{l}\text { Milder aggressiveness of } \\
\text { chemically-induced } \\
\text { colorectal tumors in rats }\end{array}$ & (33) \\
\hline $\begin{array}{l}\text { B. bifidum }+B \text {. breve } \\
+B \text {. longum }+B \text {. } \\
\text { lactis }\end{array}$ & $\begin{array}{l}\text { Administrations of } 1 \times 10^{9} \text { CFU } 7 \text { and } 14 \\
\text { days after tumor implantation }\end{array}$ & $\begin{array}{l}\text { Immunotherapy with } 100 \mu \mathrm{g} \alpha \mathrm{PD}-\mathrm{L} 1 \mathrm{mAb} \\
7,10,13 \text {, and } 16 \text { days after tumor } \\
\text { implantation }\end{array}$ & $\begin{array}{l}\text { Decreased tumor volume in } \\
\text { mice implanted with } \\
\text { melanoma }\end{array}$ & (34) \\
\hline $\begin{array}{l}\text { A. muciniphila or } A \text {. } \\
\text { muciniphila }+ \text { E. Hirae }\end{array}$ & $\begin{array}{l}\text { Five } 10^{9} \mathrm{CFU} / \mathrm{mL} \text { administrations, the first } \\
24 \mathrm{~h} \text { before the first injection of anti PD- } 1 \\
\mathrm{mAb} \text { and subsequently four times on the } \\
\text { same day as anti-PD- } 1 \mathrm{mAb} \text { therapy }\end{array}$ & $\begin{array}{l}\text { Four immunotherapy administrations at } 3 \\
\text { day intervals of } 250 \mu \mathrm{g} \text { anti-PD- } 1 \mathrm{mAb}\end{array}$ & $\begin{array}{l}\text { Reduced tumor size in mice } \\
\text { with implanted melanoma or } \\
\text { sarcoma }\end{array}$ & (36) \\
\hline E. coli Nissle 1917 & $\begin{array}{l}\text { Daily administration of } 1 \times 10^{9} \text { CFU for } 22 \\
\text { (liver cancer) or } 27 \text { days (breast cancer) } \\
\text { strarting on the day of tumor implantation }\end{array}$ & $\begin{array}{l}45 \mathrm{mg} / \mathrm{kg} \text { of anti-TGF- } \beta \text { immunotherapy } \\
\text { for } 7 \text { consecutive days }\end{array}$ & $\begin{array}{l}\text { Decreased tumor size and } \\
\text { inhibition of metastatic } \\
\text { potential in mice implanted } \\
\text { with hepatocellular } \\
\text { carcinoma or breast cancer }\end{array}$ & (35) \\
\hline
\end{tabular}

successfully used to alleviate 5-FU-induced intestinal toxicity. Oral intake of B. bifidum G9-1, before and during 5-FU administration in mice significantly reduced the body weight loss and the intestinal damage, as assessed by a minor shortening of the small intestine, of the villus length and a minor destruction of the crypts. In addition, a milder inflammatory response and attenuation of dysbiosis were observed upon probiotic treatment (40). Similar results were obtained in rats injured with a single dose of 5 -FU and administered with $B$. infantis starting before drug injection, in which loss of body weight, villus shortening, and diarrhea occurrence, as well as expression of inflammatory factors were alleviated compared to animals only treated with chemotherapy (41). Similarly, administration of a mix of the four probiotical strains B. breve DM8310, L. acidophilus DM8302, L. casei DM8121, and S. thermophilus DM8309 to rats concomitantly treated with 5-FU caused a milder intestinal damage, as assessed by decreased severity of histological score, increased villus length, crypt depth, and mucus layer, lower expression of inflammatory cytokines and inflammatory markers, compared to rats only receiving 5FU (42). Furthermore, 5-FU-induced intestinal mucositis was ameliorated in a mouse study by Yeung et al. (43). Animals were injected with 5-FU and concurrently administered with saline, $L$. casei variety rhamnosus or a mix of L. acidophilus and B. bifidum. In both probiotic treatments, body weight loss and diarrhea were less severe, villus shortening was decreased, the crypt depth restored and the expression of pro-inflammatory cytokines suppressed (43). Another chemotherapeutic drug frequently leading to intestinal toxicity is irinotecan, administered to treat advanced colorectal cancer. A pilot study on human cancer patients receiving irinotecan reported a preventive effect against diarrhea for a commercial probiotic formula containing the following 10 bacterial strains: B. breve HA-129, B. bifidum HA132, B. longum HA-135, L. rhamnosus HA-111, L. acidophilus HA-122, L. casei HA-108, L. plantarum HA-119, S. thermophilus HA-110, L. brevis HA-112, and B. infantis HA-116. Patients taking probiotics daily during chemotherapy had less diarrhea incidence and severity, and less enterocolitis and bloating compared to those taking placebo (44). Also, the VSL\#3 probiotic mix, administered before and after chemotherapy, was tested against intestinal mucositis in rats injected with a single dose of irinotecan. Weight loss, diarrhea severity, and crypt damage were decreased, as assessed by increased epithelial proliferation and reduced apoptosis (45). Other probiotic formulations are being tested in ongoing clinical trials to evaluate their effect on intestinal damage such as the OMNi-BiOTiC ${ }^{\circledR} 10$ AAD, whose ability to reduce grade III/IV diarrhea during the FOLFIRI-based chemotherapy in metastatic colorectal cancer patients is under investigation in a Phase 2 study (NCT03705442).

The VSL\#3 formula also provided intestinal benefits in patients undergoing adjuvant radiotherapy for intestinal or cervical cancer (46). The probiotic intake along the duration of the radiation therapy schedule significantly decreased enterocolitis occurrence, incidence, and severity of diarrhea and number of daily bowel movements, and delayed the use of antidiarrheal drugs (46). Likewise, the severity grade of diarrhea and the need to take anti-diarrheal drugs in cervical cancer carriers undergoing radiotherapy concurrent with cisplatin chemotherapy were significantly decreased in those patients administered with L. acidophilus plus B. bifidum-based 
TABLE 2 | Effects of probiotic intake on anticancer therapies' toxicity.

\begin{tabular}{llll}
\hline Probiotic(s) & $\begin{array}{l}\text { Probiotic dosage and } \\
\text { treatment scheme }\end{array}$ & Therapeutic treatment scheme & Effect(s)
\end{tabular}

L. rhamnosus GG
B. bifidum G9-1

B. infantis

B. breve DM8310 + L. acidophilus DM8302 + L. casei DM8121 + S.

$L$. casei variety rhamnosus or $L$. Acidophilus + B. Bifidum

B. breve HA-129+B. bifidum $\mathrm{HA}-132+B$. longum $\mathrm{HA}-135+$

L. rhamnosus $\mathrm{HA}-111+$

L. acidophilus $\mathrm{HA}-122+$ L. casei

$\mathrm{HA}-108+$ L. plantarum $\mathrm{HA}-119$

+ S. thermophilus $\mathrm{HA}-110+L$. brevis $\mathrm{HA}-112+B$. infantis

HA-116

VSL\#3

VSL\#3

Daly administration of $3 \times 10^{8}$

CFU for 21 days before and days

7 after chemotherapy

Three doses/day of 450 billions/g Adjuvant post-operative radiotherapy. Total X-ray dose between 60 and 70 Gy

Bacteria during all the scheduled cycles of radiotherapy

L. acidophilus + B. bifidum

L. acidophilus LA- $5+$

B. animalis subsp. lactis BB-12

Twice/day intake of $2 \times 109$ CFU beginning 7 days before and continuing everyday during radiotherapy

Three times/daily intake of 1.75 billion bacteria for all the duration of radiotherapy

L. brevis CD2

L. brevis CD2

B. longum + L. lactis + E. faecium thermophilus DM8309
Daily intake of $12 \times 109$ bacteria Radical radiotherapy at a dose of 70 Gy in 35 during and for one week after the fractions over 7 weeks (at 5 fractions per week) end of therapy

Daily intake of $12 \times 109$ bacteria

Three capsules three times/day during all the treatmnet for up to 7 weeks

fractions over 7 weeks (at 5 fractions per wee
+ weekly cisplatin $40 \mathrm{mg} / \mathrm{m}^{2}$ for 7 doses

Intensity-modulated radiation therapy with ad dose fractionation of 68-70 Gy and 50-54 Gy to respectively + cisplatin using a weekly (40 $\left.\mathrm{mg} / \mathrm{m}^{2}\right)$ or a 3-weekly $\left(100 \mathrm{mg} / \mathrm{m}^{2}\right)$ schedule. Intensity-modulated 70 Gy of radiotherapy in 32 fractions (2.19 Gy/day, 5 day/week), with the gross tumor volume receiving 60 Gy in 32
External pelvic radiotherapy with a dose $200 \mathrm{cG}$ per fraction, five fractions per week + weekly cisplatin $40 \mathrm{mg} / \mathrm{m}^{2}$ for 6 weeks

External beam pelvic radiotherapy with the standard dose of 50 Gy with or without concurrent chemotherapy, for 37 days the macroscopic disease and low-risk regions, fractions for 45 days +3 doses of $100 \mathrm{mg} / \mathrm{m}^{2}$ cisplatin every 3 weeks
Decreased severe diarrhea, abdominal discomfort, and need to scale chemotherapy doses in colorectal cancer patients

Milder intestinal mucositis and decreased weight loss in mice occurrence, intestinal damage, and body weight loss in rats

Milder intestinal mucositis in rats

Less severe intestinal damage, diarrhea, and body weight loss in mice

Decreased diarrhea incidence and severity, reduced enterocolitis, and bloating in colorectal cancer patients severity, and intestinal dama

Decreased enterocolitis occurrence, incidence and severity of diarrhea, number of daily bowel movements, and delayed use of antidiarrheal drugs in sigmoid, rectal, or cervical cancer patients

Decreased diarrhea severity and reduced use of anti-diarrheal drugs in cervical cancer patients

Decreased diarrhea incidence and severity, reduced abdominal pain, and use of anti-diarrheal drugs in cervical cancer patients

Decreased incidence and severity of oral mucositis in head and neck cancer patients No preventive effect on oral mucositis in head and neck cancer patients

Decreased severity of oral mucositis in nasopharyngeal 
probiotic before and during radiotherapy (47). Similar results were observed in cervical cancer patients taking $L$. acidophilus LA-5 plus $B$. animalis subsp. lactis BB-12 for all the duration of the radiotherapy schedule, in which diarrhea incidence and severity were decreased together with the use of anti-diarrheal medication and the number of episodes of abdominal pain (48).

Chemo- and radiotherapy may also lead to mucositis in oropharyngeal districts, besides at the intestinal level. This event is very common in patients treated for head and neck cancers $(49,50)$. A placebo-controlled study reported a protective role for the probiotic L. brevis CD2 against this adverse effect in patients with head and neck squamous cell carcinoma treated with cisplatin-based chemotherapy and radiation therapy (51). Probiotic administration during and after the end of therapy decreased incidence and severity of oral mucositis and allowed a higher number of patients to complete the anticancer treatment compared to the placebo group (51). Another recent paper investigating the effect of the same probiotic, administered according to the same scheme, however, failed to demonstrate its preventive effect on chemoradiotherapy-induced oropharyngeal mucositis in head and neck cancer patients (50). On the other hand, another study demonstrated that head and neck cancer carriers undergoing cisplatin chemotherapy and radiotherapy and taking a probiotic mix including B. longum, L. lactis, and Enterococcus faecium all along the treatment developed less severe oral mucositis compared to the placebo group. This benefit was achieved by enhancing patients' immunity, since probiotics significantly counteracted the reduction of $\mathrm{CD} 8^{+}, \mathrm{CD} 4^{+}$, and $\mathrm{CD}^{+} \mathrm{T}$ cells induced by the anticancer treatments (49).

More details on the probiotic treatment scheme and the anticancer therapies' schedule adopted in these studies are provided in Table 2.

\section{PROBIOTICS AS VEHICLES FOR DRUG DELIVERY AND GENE THERAPY}

Another promising application of probiotics in the field of cancer treatment is represented by their use as vectors for drug delivery or gene therapy. Given the systemic toxicity of many chemoand immunotherapeutic drugs, probiotic bacteria have been engineered to locally deliver the treatment at the tumor site (5254) also by exploiting the affinity of anaerobic strains for the anaerobic tumor microenvironment (55). This has the double advantage of increasing drug efficacy and reducing adverse effects (52-54). In addition, probiotics strains have also been used to deliver anticancer proteins at the tumor site in order to inhibit its growth (55).

\section{CONCLUSION}

A substantial body of literature in recent years has tried to shed light on the role of gut microbiota in the setting of cancer development and response to therapy. The studies reviewed in this paper strongly indicate that microbiota manipulation through selected probiotics may be a promising tool to prevent cancer onset, to improve clinical efficacy, and mitigate adverse effects of the standard anticancer therapies. Most of these benefits are achieved through the modulation of the host immunity and inflammatory response (Figure 1).

Overall, this review of the literature has demonstrated that comparable successful results can be provided by the use of single probiotics strains, as well as from different combinations thereof, although the dosage, frequency, and duration of both probiotic and drug administration may vary from study to

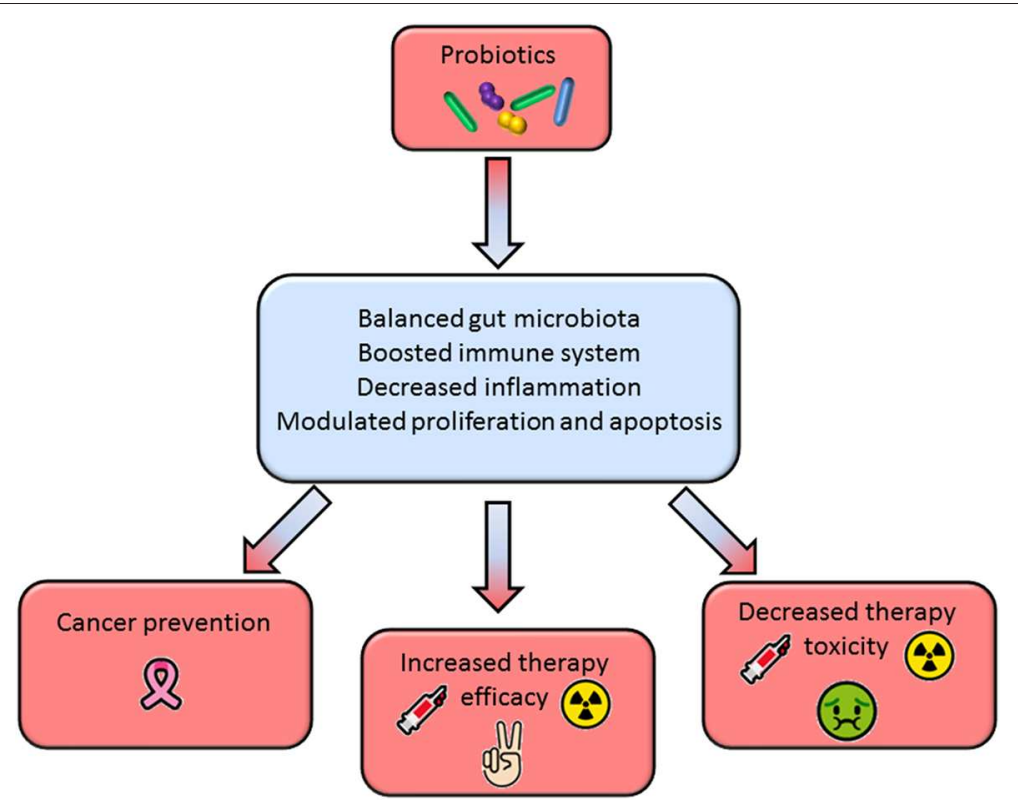

FIGURE 1 | Beneficial effects of probiotics administration in cancer prevention and therapy. 
study. In addition, it is evident that each probiotic strain or combination can prove effective in the setting of several cancers and of different chemotherapeutic protocols. However, the fact that a considerable number of reports come from experiments on preclinical models, may raise the need to further investigate the translatability of the animal findings to human patients.

Future clinical investigations on this topic are strongly required, with the aim to set up innovative approaches capable to improve clinical outcome and/or cancer patients' quality of life.

\section{REFERENCES}

1. Qin J, Li R, Raes J, Arumugam M, Burgdorf KS, Manichanh C, et al. A human gut microbial gene catalogue established by metagenomic sequencing. Nature. (2010) 464:59-65. doi: 10.1038/nature08821

2. Singh RK, Chang HW, Yan D, Lee KM, Ucmak D, Wong K, et al. Influence of diet on the gut microbiome and implications for human health. J Transl Med. (2017) 15:73. doi: 10.1186/s12967-017-1175-y

3. Flint HJ, Scott KP, Louis P, Duncan SH. The role of the gut microbiota in nutrition and health. Nat Rev Gastroenterol Hepatol. (2012) 9:57789. doi: 10.1038/nrgastro.2012.156

4. Klement RJ, Pazienza V. Impact of different types of diet on gut microbiota profiles and cancer prevention and treatment. Medicina (Kaunas). (2019) 55:84. doi: 10.3390/medicina55040084

5. Graf D, Di Cagno R, Fak F, Flint HJ, Nyman M, Saarela M, et al. Contribution of diet to the composition of the human gut microbiota. Microb Ecol Health Dis. (2015) 26:26164. doi: 10.3402/mehd.v26.26164

6. Joint FAO/WHO Working Group Report on Drafting Guidelines for the Evaluation of Probiotics in Food. London, ON (2002).

7. Panebianco C, Andriulli A, Pazienza V. Pharmacomicrobiomics: exploiting the drug-microbiota interactions in anticancer therapies. Microbiome. (2018) 6:92. doi: 10.1186/s40168-018-0483-7

8. Fijan S. Microorganisms with claimed probiotic properties. An overview of recent literature. Int J Environ Res Public Health. (2014) 11:474567. doi: 10.3390/ijerph110504745

9. Food Agriculture Organization of the United Nations/World Health Organization FAO/WHO. Guidelines for the Evaluation of Probiotics in Food; Joint FAO/WHO Working Group on Drafting Guidelines for the Evaluation of Probiotics in Food. London, ON (2002).

10. Sutula J, Coulthwaite LA, Thomas LV, Verran J. The effect of a commercial probiotic drink containing Lactobacillus casei strain shirota on oral health in healthy dentate people. Microb Ecol Health Dis. (2013) 24:112. doi: 10.3402/mehd.v24i0.21003

11. Yamazaki K, Tsunoda A, Sibusawa M, Tsunoda Y, Kusano M, Fukuchi K, et al. The effect of an oral administration of Lactobacillus casei strain Shirota on azoxymethane-induced colonic aberrant crypt foci and colon cancer in the rat. Oncol Rep. (2000) 7:977-82. doi: 10.3892/or.7.5.977

12. Toi M, Hirota S, Tomotaki A, Sato N, Hozumi Y, Anan K, et al. Probiotic beverage with soy isoflavone consumption for breast cancer prevention: a case-control study. Curr Nutr Food Sci. (2013) 9:194200. doi: 10.2174/15734013113099990001

13. Kaga C, Takagi A, Kano M, Kado S, Kato I, Sakai M, et al. Lactobacillus casei Shirota enhances the preventive efficacy of soymilk in chemically induced breast cancer. Cancer Sci. (2013) 104:1508-14. doi: 10.1111/ cas. 12268

14. Ishikawa H, Akedo I, Otani T, Suzuki T, Nakamura T, Takeyama I, et al. Randomized trial of dietary fiber and Lactobacillus casei administration for prevention of colorectal tumors. Int J Cancer. (2005) 116:7627. doi: $10.1002 / \mathrm{ijc} .21115$

15. Kassayova M, Bobrov N, Strojny L, Kiskova T, Mikes J, Demeckova V, et al. Preventive effects of probiotic bacteria Lactobacillus plantarum and dietary fiber in chemically-induced mammary carcinogenesis. Anticancer Res. (2014) 34:4969-75.

\section{AUTHOR CONTRIBUTIONS}

All authors listed have made a substantial, direct and intellectual contribution to the work, and approved it for publication.

\section{ACKNOWLEDGMENTS}

This research has been supported by Associazione Italiana Ricerca sul Cancro (AIRC) under IG 2019-ID. 23006 projectP.I. Pazienza Valerio and from Italian Ministry of Health Ricerca Corrente 2018-2020.

16. Lenoir M, Del Carmen S, Cortes-Perez NG, Lozano-Ojalvo D, MunozProvencio D, Chain F, et al. Lactobacillus casei BL23 regulates Treg and Th17 T-cell populations and reduces DMH-associated colorectal cancer. $J$ Gastroenterol. (2016) 51:862-73. doi: 10.1007/s00535-015-1158-9

17. Jacouton E, Chain F, Sokol H, Langella P, Bermudez-Humaran LG. Probiotic strain Lactobacillus casei BL23 prevents colitis-associated colorectal cancer. Front Immunol. (2017) 8:1553. doi: 10.3389/fimmu.2017.01553

18. Yazdi MH, Soltan Dallal MM, Hassan ZM, Holakuyee M, Agha Amiri S, Abolhassani M, et al. Oral administration of Lactobacillus acidophilus induces IL-12 production in spleen cell culture of BALB/c mice bearing transplanted breast tumour. Br J Nutr. (2010) 104:227-32. doi: 10.1017/S0007114510000516

19. Kuugbee ED, Shang X, Gamallat Y, Bamba D, Awadasseid A, Suliman MA, et al. Structural change in microbiota by a probiotic cocktail enhances the gut barrier and reduces cancer via TLR2 signaling in a rat model of colon cancer. Dig Dis Sci. (2016) 61:2908-20. doi: 10.1007/s10620-016-4238-7

20. Cario E, Gerken G, Podolsky DK. Toll-like receptor 2 controls mucosal inflammation by regulating epithelial barrier function. Gastroenterology. (2007) 132:1359-74. doi: 10.1053/j.gastro.2007.02.056

21. Lowe EL, Crother TR, Rabizadeh S, Hu B, Wang H, Chen S, et al. Toll-like receptor 2 signaling protects mice from tumor development in a mouse model of colitis-induced cancer. PLoS One. (2010) 5:e13027. doi: 10.1371/journal.pone.0013027

22. Gamallat Y, Meyiah A, Kuugbee ED, Hago AM, Chiwala G, Awadasseid A, et al. Lactobacillus rhamnosus induced epithelial cell apoptosis, ameliorates inflammation and prevents colon cancer development in an animal model. Biomed Pharmacother. (2016) 83:536-41. doi: 10.1016/j.biopha.2016.07.001

23. Chen ZF, Ai LY, Wang JL, Ren LL, Yu YN, Xu J, et al. Probiotics Clostridium butyricum and Bacillus subtilis ameliorate intestinal tumorigenesis. Future Microbiol. (2015) 10:1433-45. doi: 10.2217/fmb.15.66

24. Chen D, Jin D, Huang S, Wu J, Xu M, Liu T, et al. Clostridium butyricum, a butyrate-producing probiotic, inhibits intestinal tumor development through modulating Wnt signaling and gut microbiota. Cancer Lett. (2019) 469:45667. doi: 10.1016/j.canlet.2019.11.019

25. MacDonald BT, Tamai K, He X. Wnt/ $\beta$-catenin signaling: components, mechanisms, and diseases. Dev Cell. (2009) 17:9-26. doi: 10.1016/j.devcel.2009.06.016

26. Talero E, Bolivar S, Avila-Roman J, Alcaide A, Fiorucci S, Motilva V. Inhibition of chronic ulcerative colitis-associated adenocarcinoma development in mice by VSL\#3. Inflamm Bowel Dis. (2015) 21:1027-37. doi: 10.1097/MIB.00000000000 00346

27. Pala V, Sieri S, Berrino F, Vineis P, Sacerdote C, Palli D, et al. Yogurt consumption and risk of colorectal cancer in the Italian European prospective investigation into cancer and nutrition cohort. Int J Cancer. (2011) 129:27129. doi: $10.1002 /$ ijc. 26193

28. Saber A, Alipour B, Faghfoori Z, Yari Khosroushahi A. Cellular and molecular effects of yeast probiotics on cancer. Crit Rev Microbiol. (2016) 43:96115. doi: 10.1080/1040841X.2016.1179622

29. Chen X, Fruehauf J, Goldsmith JD, Xu H, Katchar KK, Koon HW, et al. Saccharomyces boulardii inhibits EGF receptor signaling and intestinal tumor growth in Apc(min) mice. Gastroenterology. (2009) 137:91423. doi: 10.1053/j.gastro.2009.05.050 
30. Wang C, Li W, Wang H, Ma Y, Zhao X, Zhang X, et al. Saccharomyces boulardii alleviates ulcerative colitis carcinogenesis in mice by reducing TNF$\alpha$ and IL- 6 levels and functions and by rebalancing intestinal microbiota. BMC Microbiol. (2019) 19:246. doi: 10.1186/s12866-019-1610-8

31. Naito S, Koga H, Yamaguchi A, Fujimoto N, Hasui Y, Kuramoto H, et al. Prevention of recurrence with epirubicin and Lactobacillus casei after transurethral resection of bladder cancer. J Urol. (2008) 179:48590. doi: 10.1016/j.juro.2007.09.031

32. Gui QF, Lu HF, Zhang CX, Xu ZR, Yang YH. Well-balanced commensal microbiota contributes to anti-cancer response in a lung cancer mouse model. Genet Mol Res. (2015) 14:5642-51. doi: 10.4238/2015.May.25.16

33. Genaro SC, Lima de Souza Reis LS, Reis SK, Rabelo Socca EA, Favaro WJ. Probiotic supplementation attenuates the aggressiveness of chemically induced colorectal tumor in rats. Life Sci. (2019) 237:116895. doi: 10.1016/j.lfs.2019.116895

34. Sivan A, Corrales L, Hubert N, Williams JB, Aquino-Michaels K, Earley ZM, et al. Commensal Bifidobacterium promotes antitumor immunity and facilitates anti-PD-L1 efficacy. Science. (2015) 350:1084-9. doi: 10.1126/science.aac4255

35. Shi L, Sheng J, Wang M, Luo H, Zhu J, Zhang B, et al. Combination therapy of TGF- $\beta$ blockade and commensal-derived probiotics provides enhanced antitumor immune response and tumor suppression. Theranostics. (2019) 9:4115-29. doi: 10.7150/thno.35131

36. Routy B, Le Chatelier E, Derosa L, Duong CPM, Alou MT, Daillere R, et al. Gut microbiome influences efficacy of PD-1-based immunotherapy against epithelial tumors. Science. (2018) 359:91-7. doi: 10.1126/science.aan3706

37. Spencer CN, Gopalakrishnan V, McQuade J, Andrews M, Helmink B, Khan $\mathrm{M}$, et al. Abstract (2838). The gut microbiome (GM) and immunotherapy response are influenced by host lifestyle factors. Cancer Res. (2020) 79:2838. doi: 10.1158/1538-7445.AM2019-2838

38. Peterson DE, Bensadoun RJ, Roila F. Management of oral and gastrointestinal mucositis: ESMO clinical practice guidelines. Ann Oncol. (2011) 22(Suppl 6):vi78-84. doi: 10.1093/annonc/mdr391

39. Osterlund P, Ruotsalainen T, Korpela R, Saxelin M, Ollus A, Valta P, et al. Lactobacillus supplementation for diarrhoea related to chemotherapy of colorectal cancer: a randomised study. Br J Cancer. (2007) 97:102834. doi: 10.1038/sj.bjc.6603990

40. Kato S, Hamouda N, Kano Y, Oikawa Y, Tanaka Y, Matsumoto K, et al. Probiotic Bifidobacterium bifidum G9-1 attenuates 5-fluorouracil-induced intestinal mucositis in mice via suppression of dysbiosis-related secondary inflammatory responses. Clin Exp Pharmacol Physiol. (2017) 44:101725. doi: 10.1111/1440-1681.12792

41. Yuan KT, Yu HL, Feng WD, Chong P, Yang T, Xue CL, et al. Bifidobacterium infantis has a beneficial effect on 5-fluorouracil-induced intestinal mucositis in rats. Benef Microbes. (2015) 6:113-8. doi: 10.3920/BM2013.0095

42. Tang Y, Wu Y, Huang Z, Dong W, Deng Y, Wang F, et al. Administration of probiotic mixture DM\#1 ameliorated 5-fluorouracilinduced intestinal mucositis and dysbiosis in rats. Nutrition. (2017) 33:96-104. doi: 10.1016/j.nut.2016.05.003

43. Yeung CY, Chan WT, Jiang CB, Cheng ML, Liu CY, Chang SW, et al. Amelioration of chemotherapy-induced intestinal mucositis by orally administered probiotics in a mouse model. PLoS One. (2015) 10:e0138746. doi: 10.1371/journal.pone.01 38746

44. Mego M, Chovanec J, Vochyanova-Andrezalova I, Konkolovsky P, Mikulova M, Reckova M, et al. Prevention of irinotecan induced diarrhea by probiotics.
A randomized double blind, placebo controlled pilot study. Complement Ther Med. (2015) 23:356-62. doi: 10.1016/j.ctim.2015.03.008

45. Bowen JM, Stringer AM, Gibson RJ, Yeoh AS, Hannam S, Keefe DM. VSL\#3 probiotic treatment reduces chemotherapy-induced diarrhea and weight loss. Cancer Biol Ther. (2007) 6:1449-54. doi: 10.4161/cbt.6.9.4622

46. Delia P, Sansotta G, Donato V, Frosina P, Messina G, De Renzis C, et al. Use of probiotics for prevention of radiation-induced diarrhea. World $J$ Gastroenterol. (2007) 13:912-5. doi: 10.3748/wjg.v13.i6.912

47. Chitapanarux I, Chitapanarux T, Traisathit P, Kudumpee S, Tharavichitkul E, Lorvidhaya V. Randomized controlled trial of live Lactobacillus acidophilus plus Bifidobacterium bifidum in prophylaxis of diarrhea during radiotherapy in cervical cancer patients. Radiat Oncol. (2010) 5:31. doi: 10.1186/1748-717X-5-31

48. Linn YH, Thu KK, Win NHH. Effect of probiotics for the prevention of acute radiation-induced diarrhoea among cervical cancer patients: a randomized double-blind placebo-controlled study. Probiotics Antimicrob Proteins. (2019) 11:638-47. doi: 10.1007/s12602-018-9408-9

49. Jiang C, Wang H, Xia C, Dong Q, Chen E, Qiu Y, et al. A randomized, doubleblind, placebo-controlled trial of probiotics to reduce the severity of oral mucositis induced by chemoradiotherapy for patients with nasopharyngeal carcinoma. Cancer. (2019) 125:1081-90. doi: 10.1002/cncr.31907

50. De Sanctis V, Belgioia L, Cante D, MR LAP, Caspiani O, Guarnaccia R, et al. Lactobacillus brevis $\mathrm{CD} 2$ for prevention of oral mucositis in patients with head and neck tumors: a multicentric randomized study. Anticancer Res. (2019) 39:1935-42. doi: 10.21873/anticanres. 13303

51. Sharma A, Rath GK, Chaudhary SP, Thakar A, Mohanti BK, Bahadur S. Lactobacillus brevis CD2 lozenges reduce radiation- and chemotherapyinduced mucositis in patients with head and neck cancer: a randomized double-blind placebo-controlled study. Eur J Cancer. (2012) 48:87581. doi: 10.1016/j.ejca.2011.06.010

52. Song Q, Zheng C, Jia J, Zhao H, Feng Q, Zhang H, et al. A Probiotic spore-based oral autonomous nanoparticles generator for cancer therapy. $A d v$ Mater. (2019) 31:e1903793. doi: 10.1002/adma.201903793

53. Singh S, Kotla NG, Tomar S, Maddiboyina B, Webster TJ, Sharma D, et al. A nanomedicine-promising approach to provide an appropriate colon-targeted drug delivery system for 5-fluorouracil. Int J Nanomedicine. (2015) 10:717582. doi: $10.2147 /$ IJN.S89030

54. Gurbatri CR, Lia I, Vincent R, Coker C, Castro S, Treuting $\mathrm{PM}$, et al. Engineered probiotics for local tumor delivery of checkpoint blockade nanobodies. Sci Transl Med. (2020) 12:eaax0876. doi: 10.1126/scitranslmed.aax0876

55. He L, Yang H, Tang J, Liu Z, Chen Y, Lu B, et al. Intestinal probiotics E. coli Nissle 1917 as a targeted vehicle for delivery of p53 and Tum-5 to solid tumors for cancer therapy. J Biol Eng. (2019) 13:58. doi: 10.1186/s13036-019-0189-9

Conflict of Interest: The authors declare that the research was conducted in the absence of any commercial or financial relationships that could be construed as a potential conflict of interest.

Copyright (C) 2020 Panebianco, Latiano and Pazienza. This is an open-access article distributed under the terms of the Creative Commons Attribution License (CC BY). The use, distribution or reproduction in other forums is permitted, provided the original author(s) and the copyright owner(s) are credited and that the original publication in this journal is cited, in accordance with accepted academic practice. No use, distribution or reproduction is permitted which does not comply with these terms. 